\title{
CORRESPONDENCE
}

\section{SENSITIVITY OF WIRE RESISTANCE STRAIN GAUGES}

In his paper, "Modern Methods of Testing Aero-engines and Power Plants" (June 1950 JournaL, A. C. Lovesey), I was surprised to see Mr. Lovesey's statement (p. 350) that, other things being equal, the sensitivity of wire resistance strain gauges varies directly as their resistivity. I gather from the remainder of the text that he meant "resistance" rather than " resistivity."

Surely, this dependance of sensitivity on resistance is quite incorrect, although it is a fallacy which is far too frequently encountered. Sensitivity depends solely on the material from which the wire is made, and on the manner in which the gauge is wound insofar as this affects the proportion of the total length of wire in the gauge which is actually subjected to strain. The following figures for nickel chrome gauges, which are taken from Dobie and Isaacs' book, "Electric Resistance Strain Gauges," will illustrate my point :-

$\begin{array}{cccc}\text { Gauge Manufacturer } & \begin{array}{c}\text { Nominal } \\ \text { Resistance } \\ \text { (ohms) }\end{array} & \begin{array}{c}\text { Length } \\ \text { (inch) }\end{array} & \text { Sensitivity } \\ \text { Rotol } & 200 & 0.5 & 1.5 \\ \text { "” Havilland } & 10,000 & 0.6 & 1.7 \\ \text { " } & 2,400 & 1.75 & 2.2 \\ & 8,000 & 1.75 & 2.2\end{array}$

It will be seen that the sensitivity varies between 1.5 and 2.2 , there being very little increase in sensitivity as the gauge resistance is increased from 200 to $10,000 \mathrm{ohms}$.

The great advantage of the high resistance strain gauge when measuring strains in moving parts is its large absolute change in resistance for a given strain. If this absolute change can be made sufficiently large as compared with changes in resistance which occur at brushes and slip rings while running, it can reduce considerably the effect which these unwanted changes have on the accuracy of the observed results; but it has no advantage where sensitivity is concerned.

S. B. Bailey, Associate Fellow

Mr. Bailey is quite correct. The paper would have been correct if the passage in question had read: "other things being equal the usable sensitivity of wire resistance strain gauges used through mercury type slip rings varies directly as their resistance."

The point is that we are limited in the current that we can pass through the slip-rings for a given background "mush" and the voltage of the signal that is obtained for a given strain is proportional to the strain gauge resistance. As Mr. Bailey points out it is misleading to refer to this voltage for a given stress as the sensitivity, a term which is defined as the proportional change in resistance for unit strain.

A. C. Lovesey, Fellow 